\title{
Characterization of Shewanella oneidensis MtrC: a cell-surface decaheme cytochrome involved in respiratory electron transport to extracellular electron acceptors
}

\author{
Robert S. Hartshorne · Brian N. Jepson · Tom A. Clarke • Sarah J. Field • \\ Jim Fredrickson · John Zachara $\cdot$ Liang Shi $\cdot$ Julea N. Butt · David J. Richardson
}

Received: 18 April 2007/Accepted: 9 July 2007/Published online: 14 August 2007

(C) SBIC 2007

\begin{abstract}
MtrC is a decaheme $c$-type cytochrome associated with the outer cell membrane of $\mathrm{Fe}(\mathrm{III})$-respiring species of the Shewanella genus. It is proposed to play a role in anaerobic respiration by mediating electron transfer to extracellular mineral oxides that can serve as terminal electron acceptors. The present work presents the first spectropotentiometric and voltammetric characterization of $\mathrm{MtrC}$, using protein purified from Shewanella oneidensis MR-1. Potentiometric titrations, monitored by UV-vis absorption and electron paramagnetic resonance (EPR) spectroscopy, reveal that the hemes within MtrC titrate over a broad potential range spanning between approximately +100 and approximately $-500 \mathrm{mV}$ (vs. the standard hydrogen electrode). Across this potential window the UVvis absorption spectra are characteristic of low-spin $c$-type hemes and the EPR spectra reveal broad, complex features that suggest the presence of magnetically spin-coupled lowspin $c$-hemes. Non-catalytic protein film voltammetry of $\mathrm{MtrC}$ demonstrates reversible electrochemistry over a potential window similar to that disclosed spectroscopically. The voltammetry also allows definition of kinetic properties
\end{abstract}

R. S. Hartshorne - B. N. Jepson - T. A. Clarke

S. J. Field · J. N. Butt $(\bowtie) \cdot$ D. J. Richardson $(\bowtie)$

Centre for Metalloprotein Spectroscopy and Biology,

School of Biological Sciences and School of Chemical

Sciences and Pharmacy,

University of East Anglia,

Norwich NR4 7TJ, UK

e-mail: j.butt@uea.ac.uk

D. J. Richardson

e-mail: d.richardson@uea.ac.uk

J. Fredrickson · J. Zachara $\cdot$ L. Shi

Pacific Northwest National Laboratory,

P.O. Box 999, Richland,

WA 99352, USA of MtrC in direct electron exchange with a solid electrode surface and during reduction of a model $\mathrm{Fe}(\mathrm{III})$ substrate. Taken together, the data provide quantitative information on the potential domain in which MtrC can operate.

Keywords Cytochrome $c$. Iron respiration . Electron transfer - Protein film voltammetry . Electron paramagnetic resonance
Abbreviations
CAPS 3-(Cyclohexyl)-1-aminopropanesulfonic acid
CHAPS 3-[(3-Cholamidopropyl) dimethylammonio]propanesulfonic acid
CHES $N$-Cyclohexyl-2-aminoethanesulfonic acid
EPR Electron paramagnetic resonance
HEPES $N$-(2-Hydroxyethyl)piperazine- $N^{\prime}$ - ethanesulfonic acid
MES 2-Morpholinoethanesulfonic acid
$\mathrm{MQH}_{2} \quad$ Menaquinol
PAGE Polyacrylamide gel electrophoresis
PFV Protein film voltammetry
SDS Sodium dodecyl sulfate
SHE Standard hydrogen electrode

\section{Introduction}

Members of the Shewanella species are Gram-negative $\gamma$-proteobacteria and have been isolated from many aquatic and marine environments [1]. Shewanella species are renowned for their incredible respiratory versatility and are reportedly able to use over 20 terminal electron acceptors for respiration $[2,3]$. These include metal oxide minerals, particularly those of $\mathrm{Fe}(\mathrm{III})$, such as hematite and goethite. 
$\mathrm{Fe}(\mathrm{III})$ mineral oxide reduction is one of the most widespread respiratory processes in anoxic zones and has environmental significance, influencing several biogeochemical cycles [4-7]. Fe(III) is highly insoluble in most environments at circumneutral $\mathrm{pH}$ and, unlike other terminal electron acceptors such as oxygen, nitrate and sulfate, cannot freely diffuse into cells. For respiration of insoluble substrates the bacterium must transfer electrons from the central cell metabolism to the iron(III) oxide surface. It is generally considered that electrons are transferred by electron transfer proteins (or quinones), in the inner membrane, to a series of multiheme $c$-type cytochromes. These cytochromes transfer electrons from the periplasm to the extracellular side of the outer cell membrane and across the microbe-mineral oxidant interface [5, 8-11].

Electron transport proteins proposed to be involved in $\mathrm{Fe}(\mathrm{III})$ respiration in Shewanella oneidensis MR-1 include an inner-membrane periplasmic tetraheme quinol dehydrogenase (CymA) [8, 12], two periplasmic decaheme cytochromes (MtrD and MtrA) [10, 13], periplasmic tetraheme cytochrome (Stc) $[14,15]$, the cytochrome domain of $\mathrm{Fe}$ (III)-induced flavocytochrome $c_{3}$, [16] two putative outer-membrane $\beta$-barrel proteins (MtrE and MtrB) [1719] and three outer-membrane decaheme cytochromes (MtrF, OmcA and MtrC) [11, 18, 20, 21]. Although genetic studies have identified specific proteins that are involved in Fe(III) respiration in Shewanella sp. [8-11, 13, 14, 17], mechanistic details of the electron transfer process are as yet unknown. It is postulated that following oxidation of menaquinol $\left(\mathrm{MQH}_{2}\right)$ by CymA, electrons are transferred via periplasmic multiheme cytochromes (MtrA and/or Stc) to outer-membrane-associated multiheme cytochromes, OmcA and MtrC (Fig. 1) [5, 8-11, 13, 14, 16-18]. OmcA and $\mathrm{MtrC}$ protein sequences both comprise ten putative $c$ heme binding site motifs $(\mathrm{CXXCH}$, where $\mathrm{X}$ is any residue) and a lipid-binding motif for anchoring to the outer membrane $[11,22]$. Because of their proposed location, these multiheme cytochromes are believed to function in $\mathrm{Fe}(\mathrm{III})$ respiration by mediating electron transfer across the microbe-mineral oxidant interface [5, 10, 13, 18, 22]. Significantly, a $\Delta m t r C$ strain of $S$. oneidensis MR-1 displayed a marked decrease in the ability to respire iron(III) oxides and iron(III) citrate, while retaining the ability to respire soluble terminal electron acceptors, including $\mathrm{NO}_{3}^{-}$ and $\mathrm{NO}_{2}^{-}[11,17]$. In the light of this, we present here the first spectroscopic characterization of the decaheme cytochrome MtrC. Data obtained from potentiometric and voltammetric analysis provide quantitative information on the potential and time domains in which MtrC can operate that can be considered alongside whole-cell electrochemical studies on Shewanella species and their use in microbial fuel cells [23, 24].

\section{Materials and methods}

\section{Growth conditions and protein purification}

Cultures of the $S$. oneidensis MR-1 expression strain LS306, encoding MtrC with a C-terminus tag [21, 25], were grown aerobically in Luria-Bertani medium (containing $50 \mu \mathrm{g} \mathrm{mL}^{-1}$ kanamycin) at $303 \mathrm{~K}$ overnight. For scale-up, each initial overnight culture $(10 \mathrm{~mL})$ was used to
Fig. 1 An electron transfer scheme for $\mathrm{Fe}(\mathrm{III})$ mineral oxides and nitrate reduction in Shewanella oneidensis

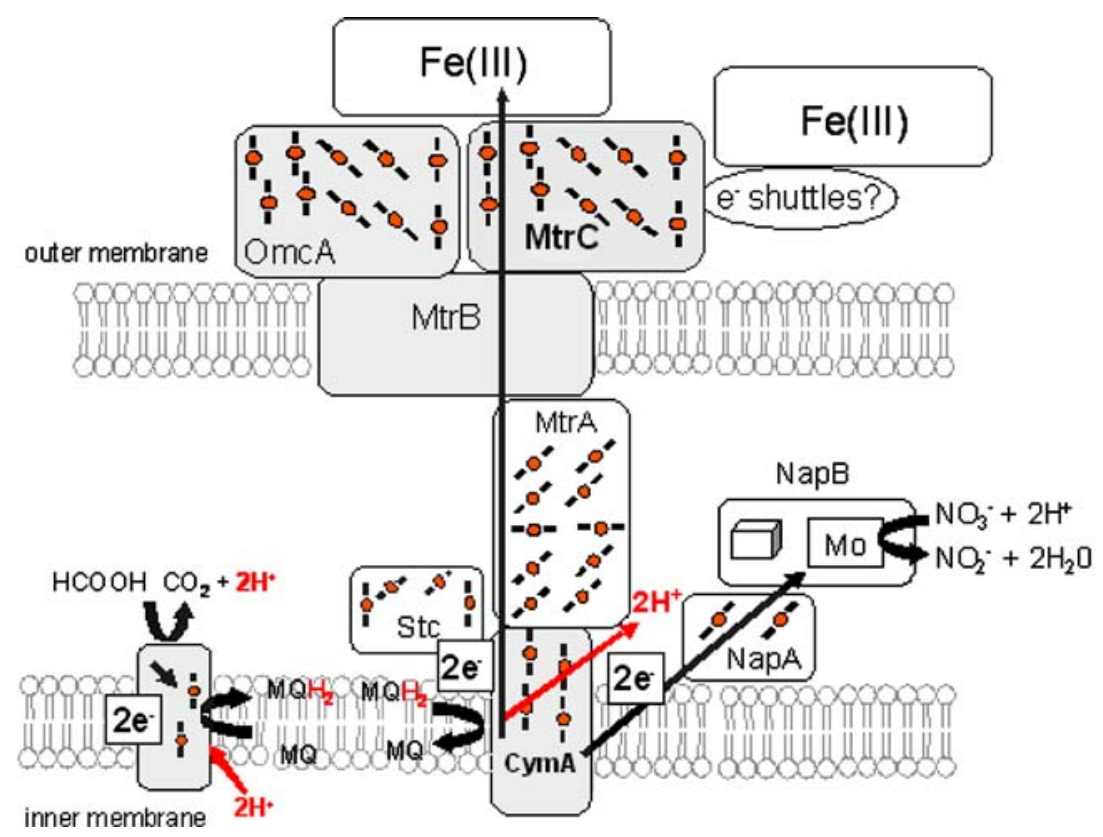


inoculate $1 \mathrm{~L}$ of fresh Luria-Bertani medium (containing $50 \mu \mathrm{g} \mathrm{mL}^{-1}$ kanamycin). For standard MtrC preparations, ten such $1 \mathrm{~L}$ cultures were grown aerobically at $303 \mathrm{~K}$ until an optical density at $600 \mathrm{~nm}$ of 0.6 was achieved and were then induced with $1 \mathrm{mM}$ L-arabinose. Cells were harvested by centrifugation $(6,000 \mathrm{~g}, 277 \mathrm{~K}, 15 \mathrm{~min})$, washed, and resuspended in $20 \mathrm{mM} \mathrm{N}$-(2-hydroxyethyl)piperazine- $N^{\prime}$-ethanesulfonic acid (HEPES), pH 7.6. Cell lysis was achieved by three passes through a French pressure cell operated at 1,000 psi. Unbroken cells and cell debris were removed by centrifugation $(15,000 \mathrm{~g}, 277 \mathrm{~K}$, $1 \mathrm{~h})$. The supernatant was centrifuged $(150,000 \mathrm{~g}, 277 \mathrm{~K}$, $1 \mathrm{~h}$ ) and the resulting pellet (i.e., the dark-red membrane fraction) was solubilized in $20 \mathrm{mM}$ HEPES, $\mathrm{pH} 7.6,0.5 \%$ $(\mathrm{wt} / \mathrm{vol}) \quad 3-[(3$-cholamidopropyl)dimethylammonio]propanesulfonic acid (CHAPS) (Buffer A), with gentle stirring for $4 \mathrm{~h}$ at $277 \mathrm{~K}$. Unsolubilized proteins were removed by centrifugation at $15,000 \mathrm{~g}$ and $277 \mathrm{~K}$ for $30 \mathrm{~min}$. The solubilized membrane fraction was applied to a (diethylamino)ethyl-Sepharose CL-6B anion-exchange column (Amersham Pharmacia Biotech) preequilibrated with buffer A. The column was washed with buffer A (four column volumes) and developed with a $\mathrm{NaCl}$ gradient $(0$ $1 \mathrm{M})$. The eluted fractions containing $\mathrm{MtrC}$ were identified by a combination of sodium dodecyl sulfate (SDS) polyacrylamide gel electrophoresis (PAGE) and heme-linked peroxidase staining. MtrC was eluted at approximately $250 \mathrm{mM} \mathrm{NaCl}$. Fractions containing MtrC were combined, dialyzed against $20 \mathrm{mM}$ HEPES, $\mathrm{pH} 7.6,0.5 \%$ (wt/vol) CHAPS, $100 \mathrm{mM} \mathrm{NaCl}$ (buffer B) and concentrated by ultrafiltration (30-kDa cutoff membrane, Amicon). The sample was applied to an S200 HR 10/30 column (Amersham Biosciences) preequilibrated with buffer B. The column was developed with equilibration buffer and fractions containing MtrC were combined and then applied to an Econo-Pack High-Q cartridge (Bio-Rad, Hercules, CA, USA) preequilibrated with buffer $B$. The column was washed with equilibration buffer (five column volumes) and developed with a $\mathrm{NaCl}$ gradient $(0.1-1 \mathrm{M})$. MtrC was eluted at approximately $0.45 \mathrm{M} \mathrm{NaCl}$. Fractions containing MtrC were dialyzed against $20 \mathrm{mM}$ HEPES, pH 7.5, $100 \mathrm{mM} \mathrm{NaCl}, 0.5 \%$ (wt/vol) CHAPS and concentrated by ultrafiltration (30-kDa cutoff membrane, Amicon). Aliquots of purified MtrC were frozen in liquid nitrogen and stored at $193 \mathrm{~K}$. Protein concentration was determined using the Bradford method with bovine serum albumin serving as the standard. The concentration of purified MtrC was also determined by UV-vis absorption spectroscopy of the air-equilibrated protein using the experimentally determined $\varepsilon_{410 \mathrm{~nm}}=1,260 \mathrm{mM}^{-1} \mathrm{~cm}^{-1}$. For quantification of the number of covalently ligated $c$-type hemes attached to MtrC, conversion into pyridine derivatives was achieved by incubating protein $(3 \mu \mathrm{M})$ with pyridine
$(2.1 \mathrm{M})$ and $\mathrm{NaOH}(75 \mathrm{mM})$ in water at room temperature for $15 \mathrm{~min}$. Sodium dithionite and potassium ferricyanide were then added to separate aliquots of the resulting solution such that the final concentrations of protein, reductant and oxidant were $2.5 \mu \mathrm{M}, 1.5 \mathrm{mM}$ and $750 \mu \mathrm{M}$, respectively. Heme content was determined using the difference molar absorption coefficient of $19.1 \mathrm{mM}^{-1} \mathrm{~cm}^{-1}$ at $550 \mathrm{~nm}$ for the pyridine ferrohemochrome minus the pyridine ferrihemochrome [26].

\section{SDS-PAGE and Western blotting}

Slab gels of $12 \%(\mathrm{wt} / \mathrm{vol})$ polyacrylamide were employed for resolution of proteins, with samples being loaded via a stacking gel of 5\% (wt/vol) polyacrylamide. Samples were prepared for electrophoresis by incubation with $3 \mathrm{M}$ urea/ $90 \mathrm{mM}$ SDS at $363 \mathrm{~K}$ for $10 \mathrm{~min}$. The presence of $c$-type cytochromes was probed for using a heme-linked peroxidase staining method [27]. Western blotting was performed using a peptide-specific affinity purified anti-MtrC antibody with goat-anti rabbit alkaline phosphatase secondary antibody (Sigma). A 5-bromo-4-chloro-3-indolyl phosphate/nitro blue tetrazolium colorimetric assay (Sigma) was used for signal detection.

\section{UV-vis spectropotentiometric titrations}

Spectropotentiometric titrations of a $2 \mu \mathrm{M}$ MtrC solution in $100 \mathrm{mM}$ HEPES, $100 \mathrm{mM} \mathrm{NaCl}, 0.5 \%$ (wt/vol) CHAPS, $\mathrm{pH} 7.5$ were performed as described previously [28] in the presence of redox mediators. The mediators $(10 \mu \mathrm{M}$ each $)$ were diaminodurene, phenazine methosulfate, phenazine ethosulfate, anthraquinone 2,6-sulfonate, anthraquinone 2sulfonate, benzyl viologen and methyl viologen. The titrations was performed at $288 \mathrm{~K}$ and UV-vis absorption spectra from 500 to $600 \mathrm{~nm}$ were collected in situ at a range of potentials in both reductive (using sodium dithionite) and oxidative (using potassium ferricyanide) titers. The change in $\alpha$-peak absorbance (referenced vs. a $562-\mathrm{nm}$ isosbestic point) was used to monitor the extent of MtrC reduction and a plot of the fraction of reduced MtrC as a function of potential was constructed. Measurements prior to, and following, titrations confirmed that the solution $\mathrm{pH}$ did not change during experimentation.

Electron paramagnetic resonance spectroscopy

Low-temperature electron paramagnetic resonance (EPR) spectroscopy was performed at $\mathrm{X}$-band frequency, using an ER200D spectrometer. The microwave bridge and 
electromagnet were interfaced to an EMX control (Bruker Biospin, Germany). A dual-mode X-band cavity (Bruker, type ER116DM) was used, where the sample temperature was modulated using an ESR-900 liquid helium flow cryostat. Spin quantification of the EPR signals were estimated by double integration and comparison with a $1 \mathrm{mM}$ $\mathrm{Cu}^{2+}$-EDTA standard, all measured under nonsaturating conditions [29]. Redox poising of samples of MtrC $(140 \mu \mathrm{M})$ in $50 \mathrm{mM}$ HEPES, $100 \mathrm{mM} \mathrm{NaCl}, 0.5 \%$ (wt/vol) CHAPS, pH 7.5 for EPR analysis was achieved under the control of a potentiostat (Autolab electrochemical analyzer under the control of GPES software) using a three-electrode cell configuration housed in an anaerobic chamber (nitrogen atmosphere with less than $2 \mathrm{ppm} \mathrm{O}_{2}$ ). Samples were introduced into a freshly polished glassy carbon pot thermostated at $288 \mathrm{~K}$ that constituted the working electrode. A platinum wire counter electrode was housed in a chamber separated from the MtrC solution via a Vycor frit and the $\mathrm{Ag} / \mathrm{AgCl}, \mathrm{KCl}$ (saturated) reference electrode $(298 \mathrm{~K})$ was in contact with the sample through a Luggin capillary tip. To facilitate electrode-MtrC equilibration a mediator solution comprising diaminodurene, phenazine methosulfate, phenazine ethosulfate, anthraquinone 2,6sulfonate, anthraquinone 2-sulfonate, benzyl viologen and methyl viologen (all at $20 \mu \mathrm{M}$ final concentration) was added to the MtrC sample. Samples were poised at the desired potential, with stirring, until the current from the sample fell to zero, indicating equilibration with the applied potential. Equilibration at each potential typically occurred within $30 \mathrm{~min}$. After the zero current potential of the cell had been confirmed to be the desired equilibration potential, a $100-\mu \mathrm{L}$ sample was immediately transferred with a gastight syringe into a custom-built quartz EPR tube (4-mm internal diameter). The gastight syringe was placed in the glove box at least 3 days before samples were poised to minimize the possibility for oxygen introduction into the sample. The EPR tubes were then rapidly sealed with Parafilm, removed from the glove box and immediately placed in liquid nitrogen, in which the sample froze over a period of 30-45 s. Potentials are reported with reference to the standard hydrogen electrode (SHE) by addition of $197 \mathrm{mV}$ to those measured.

Sedimentation equilibrium analysis

Experiments were performed using a Beckman Optima XL-I analytical ultracentrifuge equipped with scanning absorption optics and an An50Ti rotor. The MtrC partial specific volume of $0.721 \mathrm{~mL} \mathrm{~g}^{-1}$ was estimated from the amino acid sequence using SEDNTERP software [30]. MtrC samples were diluted to appropriate concentrations with $50 \mathrm{mM}$ HEPES, $150 \mathrm{mM} \mathrm{NaCl}, 0.5 \%$ (wt/vol)
CHAPS, pH 7.5 and loaded into charcoal-filled Epon double-sector cells fitted with quartz windows. Reference sectors were filled with $120 \mu \mathrm{L}$ buffer. Sedimentation equilibrium experiments were performed at $293 \mathrm{~K}$ at $6,000,8,000$ and 10,000 rpm. Concentration profiles were measured at absorption wavelengths of $440 \mathrm{~nm}(3 \mu \mathrm{M})$, $530 \mathrm{~nm}(10 \mu \mathrm{M}), 495 \mathrm{~nm}(20 \mu \mathrm{M}), 600 \mathrm{~nm}(40 \mu \mathrm{M})$ and $620 \mathrm{~nm}(60 \mu \mathrm{M})$ for the MtrC sample concentration indicated. Scans were recorded every $4 \mathrm{~h}$ and equilibrium was considered to have been reached when the absorbance values remained constant over a 4-h period. After equilibrium had been reached, five scans were recorded for each sample. The program ULTRASCAN 6.2 [31] was used to simultaneously fit the sedimentation equilibrium profiles obtained at three different speeds, to a singlespecies, non-interacting system. The molecular weight was determined by fitting the absorbance data of the equilibration runs using the exponential equation

$C(r)=C\left(r_{0}\right) \cdot \mathrm{e}^{\left(\frac{(1-p p) \omega^{2}}{2 R T} M\left(r^{2}-r_{0}^{2}\right)\right)}$,

where $C(r)$ is the concentration at radius $r, C\left(r_{0}\right)$ is the concentration at reference radius $r_{0}, M$ is the monomer molecular weight, $R$ is the universal gas constant, $T$ is the temperature, $\omega$ is the angular velocity, $\rho$ is the density of the solution and $v$ is the partial specific volume of the protein. Rearranging this equation gives

$\frac{\mathrm{d} \ln (C r)}{\mathrm{d} r^{2}}=\frac{M(1-v \rho) \omega^{2}}{2 R T}$.

For visualizing the data graphically, measured absorbance can be substituted for concentration and plots of log absorbance versus $r^{2}-r_{0}^{2} / 2$ for a single species are expected to give a straight line, the slope of which is proportional to the molecular mass of the protein.

Protein film voltammetry

Protein film voltammetry (PFV) was performed as described previously [32] except that the working electrode surface (geometric area $0.12 \mathrm{~cm}^{2}$ ) was freshly polished basal-plane graphite. Protein films were prepared using a Hamilton syringe to apply an approximately $1 \mu \mathrm{L}$ aliquot of an ice-cold $40 \mu \mathrm{M}$ MtrC solution in $50 \mathrm{mM}$ HEPES, $100 \mathrm{mM} \mathrm{NaCl}, 0.5 \%$ (wt/vol) CHAPS, $\mathrm{pH} 7.0$ to the electrode surface. Buffer-electrolyte solutions were brought to the desired $\mathrm{pH}$ by the addition of aliquots of $2 \mathrm{M} \mathrm{NaOH}$ or $2 \mathrm{M} \mathrm{HCl}$. The influence of $\mathrm{pH}$ was investigated in solutions composed of $50 \mathrm{mM}$ 2-morpholinoethanesulfonic acid (MES) (pH 6.0), HEPES (pH 7.0 and $\mathrm{pH} 8.0$ ), $N$-cyclohexyl-2-aminoethanesulfonic acid (CHES) ( $\mathrm{pH}$ 9.0) or 3-(cyclohexyl)-1-aminopropanesulfonic acid (CAPS) (pH 
10.0 and $\mathrm{pH} 11.0$ ), all with $100 \mathrm{mM} \mathrm{NaCl}$ as electrolyte. The $\mathrm{pH}$ was monitored prior to and following voltammetric experiments and remained constant. Voltammetric responses were unchanged when the buffer-electrolyte was switched from $100 \mathrm{mM} \mathrm{NaCl}$ to $350 \mathrm{mM} \mathrm{NaCl}$. Stock solutions of iron(III) citrate were prepared by dissolving iron(III) chloride 6-hydrate (98\% purity, Sigma) and citric acid $(99.7 \%$ purity, Sigma) in deionized water to give a stock solution of 1:1 molar ratio. The $\mathrm{pH}$ of the resulting solution was brought to 7.0 by additions of a $10 \mathrm{M} \mathrm{NaOH}$ solution. Following preparation, solutions were filtered through a $0.22-\mu \mathrm{m}$ nylon syringe filter and stored in lightfree conditions. Faradaic voltammetric responses were extracted from raw data using the The Utilities for Data Analysis 010716 program, kindly provided by H.A. Heering. Engineered "reticulating (cubic) splines" baselines, retaining the experimental baseline character, were constructed and subtraction from experimental voltammograms yielded the Faradaic response of MtrC.

\section{Results}

Purification and biochemical characterization of MtrC

Membrane fractions of $S$. oneidensis MR-1 were solubilized in CHAPS detergent and initially purified on a (diethylamino)ethyl anionic exchange column. Eluted fractions containing MtrC were purified further on QSepharose and S200 columns. The purified protein obtained migrated in SDS-PAGE gels as an approximately $75 \mathrm{kDa}$ Coomassie blue staining band (Fig. 2a, inset, lane 2) that also stained for heme-dependent peroxidase activity (Fig. 2a, inset, lane 3). The polypeptide was positively identified as $\mathrm{MtrC}$ by peptide fragmentation mass analysis (not shown) and via detection with MtrC-specific antibodies (Fig. 2a, inset, lane 4). The final yields of purified MtrC were routinely 5-10 $\mathrm{mg} \mathrm{L}^{-1}$ starting culture. MtrC preparations could be stored at $193 \mathrm{~K}$ for prolonged periods (more than 6 months) without noticeable deterioration, as judged by UV-vis absorption spectroscopic properties and SDS-PAGE. Highly concentrated samples could be prepared (more than $0.5 \mathrm{mM}$ ) without evidence of precipitation, indicating the suitability of the $20 \mathrm{mM}$ HEPES, $100 \mathrm{mM} \mathrm{NaCl}, 0.5 \%$ (wt/vol) CHAPS, pH 7.5 bufferelectrolyte-detergent system used.

The air-oxidized MtrC UV-vis spectrum displays a heme Soret $(\gamma)$ absorption peak centered at $410 \mathrm{~nm}$, a visible-region peak at $531 \mathrm{~nm}$ and a shoulder at $560 \mathrm{~nm}$ (Fig. 2a). This spectrum remains unaltered upon further oxidation of $\mathrm{MtrC}$ by potassium ferricyanide (data not shown). When MtrC is reduced with dithionite, the Soret $(\gamma)$ peak shifts to $419 \mathrm{~nm}$ and clearly defined $\alpha$ and $\beta$ peaks
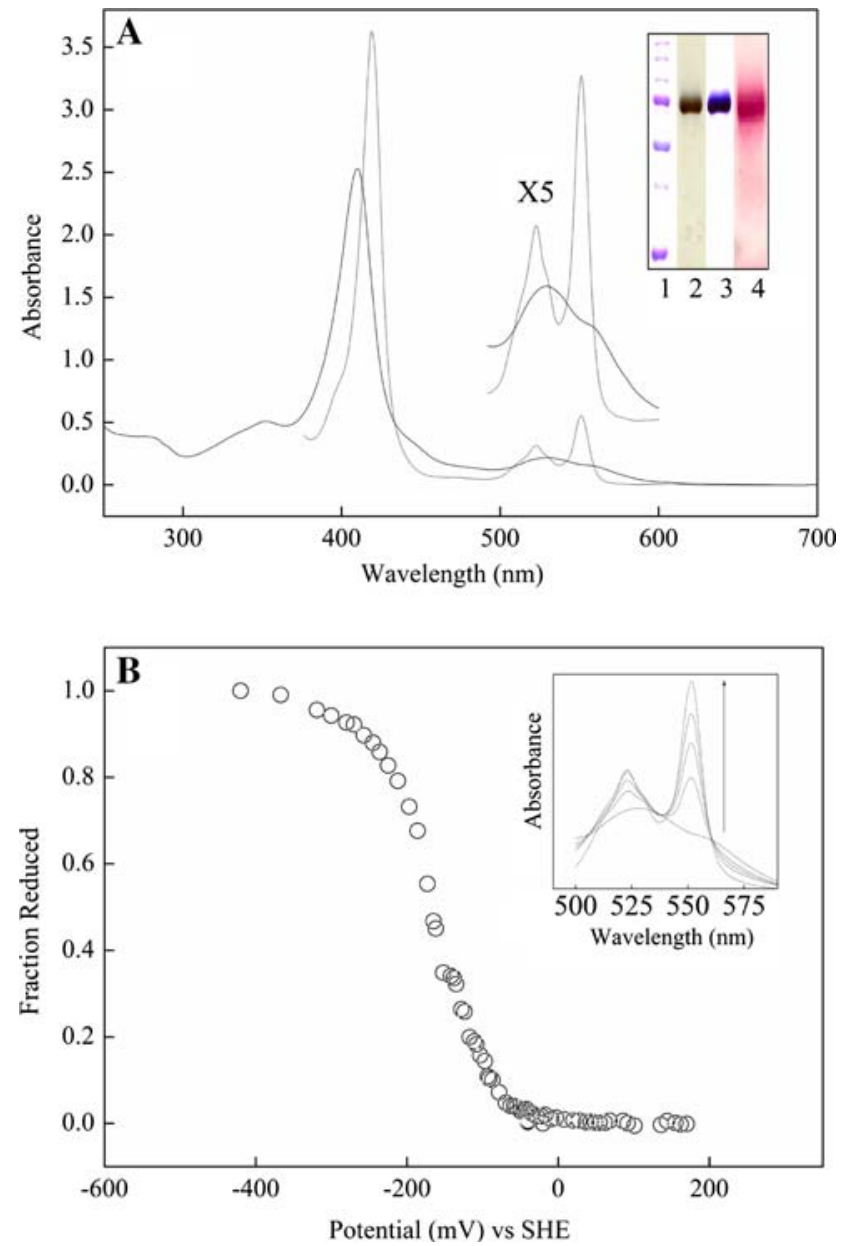

Fig. 2 UV-vis properties of MtrC. a UV-vis absorption spectrum of MtrC $(2 \mu \mathrm{M})$ in $50 \mathrm{mM}$ HEPES, pH $7.5,100 \mathrm{mM} \mathrm{NaCl}, 0.5 \%$ (wt/ vol) CHAPS. Solid line air-oxidized $\mathrm{MtrC}$, dashed line sodium dithionite reduced MtrC. Also shown is $\times 5$ amplification of the 500 600-nm absorption region. Inset: lanes 1-3 sodium dodecyl sulfate polyacrylamide gel electrophoresis (SDS-PAGE) analysis of purified Shewanella oneidensis MR-1 MtrC. Lane 1 molecular mass markers (from top to bottom: 250, 150, 100, 75, 50, 37 and $25 \mathrm{kDa}$ ); lane 2 heme-stained purified MtrC; lane 3 Coomassie blue stained purified MtrC; lane 4 purified MtrC resolved by SDS-PAGE, electroblotted and detected with anti-MtrC primary and goat-anti rabbit alkaline phosphatase secondary antibodies. b UV-vis spectropotentiometric properties of MtrC. Fraction of MtrC reduced versus potential (vs. the standard hydrogen electrode, SHE). Inset UV-vis absorption spectrum of MtrC focusing on the 500-600-nm region obtained at +241 , $-110,-140,-160$ and $-210 \mathrm{mV}$. The direction of the arrow indicates spectra collected at an increasingly negative potential. Conditions of measurement were as follows: MtrC $(2 \mu \mathrm{M})$ in $100 \mathrm{mM}$ HEPES, pH 7.5, $100 \mathrm{mM} \mathrm{NaCl}, 0.5 \%$ (wt/vol) CHAPS

are observed at 552 and $523 \mathrm{~nm}$ (Fig. 2a). The absorbance ratio of heme to total protein $(410 \mathrm{~nm} / 280 \mathrm{~nm})$ of oxidized protein was typically approximately 7.0 and an extinction coefficient at $410 \mathrm{~nm}$ of $1,260 \mathrm{mM}^{-1} \mathrm{~cm}^{-1}$ was experimentally determined. The pyridine hemochrome of MtrC displays an $\alpha$ absorption peak at $550 \mathrm{~nm}$ typical of low- 
spin $c$-type cytochromes [26, 27]. Quantitative analysis suggests the covalent attachment of 10.8 (average value from five repeat experiments) $c$ hemes correlating with the ten predicted $\mathrm{CXXCH}$ heme attachment sequences encoded within the protein sequence.

The continuous-wave, $2 \mathrm{~mW}, 10 \mathrm{~K}$ perpendicular mode $\mathrm{X}$-band EPR spectrum was dominated by a broadened rhombic-type signal with $g$ values tentatively ascribed as follows: $g_{1} \sim 3.2, \quad 3.0$ and $2.86 ; \quad g_{2} \sim 2.20 ;$ and $g_{3} \sim 1.5$ (Fig. 3a). The broadness and asymmetry of the $g_{\max } \sim 3.7-2.7$ region is consistent with a composite signal arising from multiple resonances of low-spin $c$-heme paramagnetic species [33]. The defining features of this spectrum were unchanged in ferricyanide-oxidized samples and were concentration-independent (except for signal: noise) over the range $20-100 \mu \mathrm{M}$. At increased microwave power (32 mW) the broadness of the $g_{\max } \sim 3.7-2.7$ region was reduced slightly, with the signal intensity of $g \sim 3.2$ and 2.86 features decreasing relative to that of the $g \sim 3.0$ feature. Signals due to small amounts of high-spin Fe(III) heme and adventitious Fe(III) are observed at $g \sim 6$ and $g \sim 4.3$.

The relative sensitivities of UV-vis absorption and EPR spectroscopy required an increased sample concentration for EPR analysis (more than $20 \mu \mathrm{M}$ compared with less than $5 \mu \mathrm{M}$ for UV-vis absorption spectroscopy). To assess the MtrC oligomeric conformation over this concentration range, analytical ultracentrifugation (sedimentation equilibrium) analysis was employed. Sedimentation equilibrium profiles of MtrC samples were collected at three rotor speeds $(6,000,8,000$ and $10,000 \mathrm{rpm})$ for five different MtrC concentrations (3, 10, 20, 40 and $60 \mu \mathrm{M}$ ). For each MtrC concentration, the sedimentation data collected at the three rotor speeds were simultaneously fitted to a single-species, noninteracting model. Plots of $\log$ absorbance versus $r^{2}-r^{2}($ ref $) / 2$ (Fig. 4) are expected to give a straight line, the slope of which is proportional to the molecular mass of the protein [34]. Straight-line plots with similar gradients were obtained for all five MtrC concentrations examined (Fig. 4) with the best fits yielding molecular masses of 96, 90, 89, 89 and $89 \mathrm{kDa}$ for the 3, $10,20,40$ and $60 \mu \mathrm{M}$ samples, respectively. These observed molecular masses are close to that predicted for the MtrC polypeptide with ten hemes covalently attached (approximately $85 \mathrm{kDa}$ ) and suggest a monomeric state within the concentration range examined. The 5-10 kDa of additional observed mass may be attributed to MtrC-associated CHAPS detergent.

Thermodynamic properties of MtrC

A potentiometric titration, monitored by UV-vis absorption spectroscopy, was performed to assess the thermodynamic

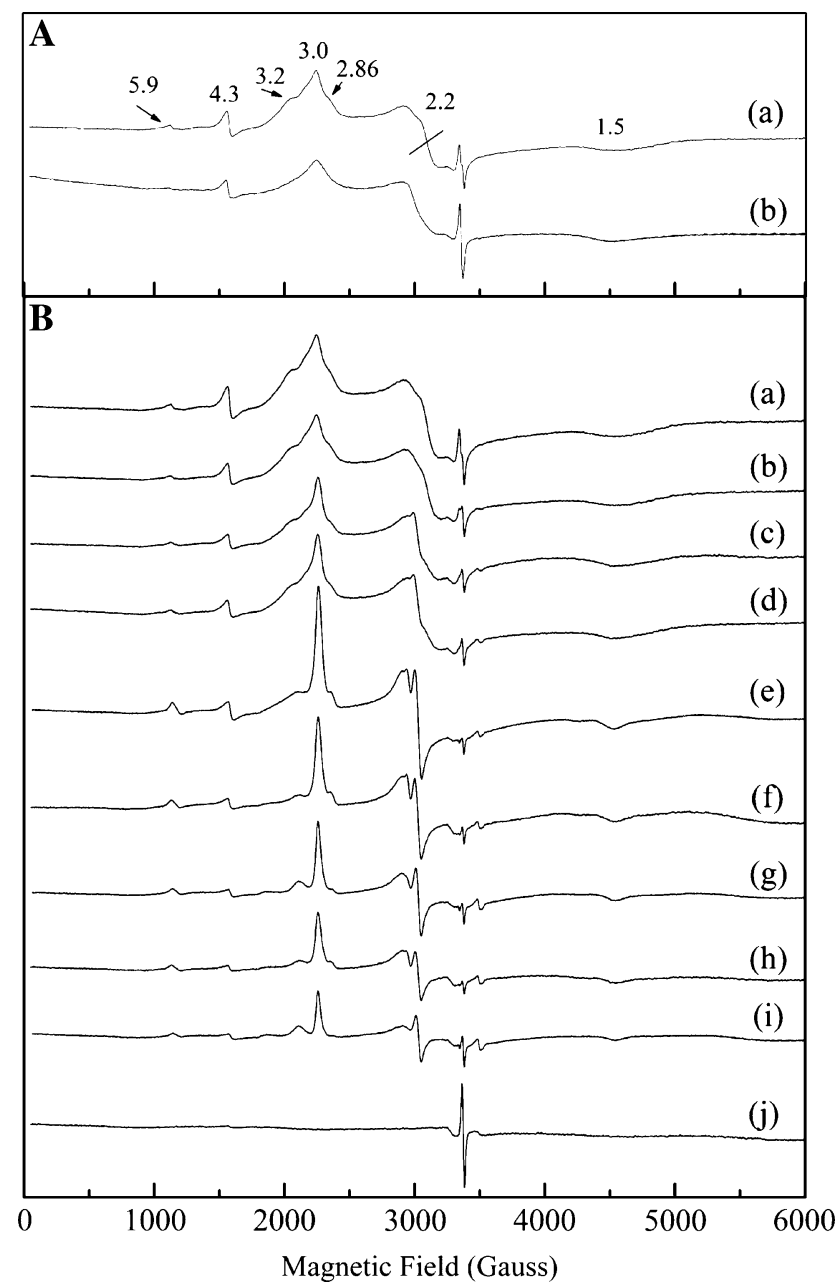

Fig. 3 Continuous-wave X-band electron paramagnetic resonance (EPR) properties of MtrC. a X-band EPR signals arising from purified MtrC. a MtrC spectrum collected at $+200 \mathrm{mV}$. Conditions of measurement as follows: MtrC $(140 \mu \mathrm{M})$ in $50 \mathrm{mM}$ HEPES, $\mathrm{pH}$ 7.5, $100 \mathrm{mM} \mathrm{NaCl}, 0.5 \%$ (wt/vol) CHAPS, temperature $10 \mathrm{~K}$, microwave power $2 \mathrm{~mW}$, microwave frequency $9.68 \mathrm{GHz}$ and modulation amplitude $10 \mathrm{G} . b$ Sample and conditions of measurement as for $a$ above but the spectrum was collected at 32-mW microwave power. b EPR spectra of MtrC poised at $a+100 \mathrm{mV}, b 0 \mathrm{mV}, c$ $-100 \mathrm{mV}, d-150 \mathrm{mV}, e-175 \mathrm{mV}, f-200 \mathrm{mV}, g-300 \mathrm{mV}, h$ $-400 \mathrm{mV}, i-450 \mathrm{mV}$ and $j-500 \mathrm{mV}$. The sharp derivative at $g \sim 2$ in $j$ arises from reduced mediators. Conditions of measurement as follows: $\mathrm{MtrC}(140 \mu \mathrm{M})$ in $50 \mathrm{mM}$ HEPES, pH 7.5, $100 \mathrm{mM}$ $\mathrm{NaCl}, 0.5 \%$ (wt/vol) CHAPS, temperature $10 \mathrm{~K}$, microwave power $2 \mathrm{~mW}$, microwave frequency $9.68 \mathrm{GHz}$ and modulation amplitude $10 \mathrm{G}$

properties of MtrC in solution. UV-vis absorption spectra of MtrC were obtained at a range of potentials spanning between +400 and $-450 \mathrm{mV}$ and the normalized $\alpha$-peak absorbance was plotted versus potential (Fig. 2b). Spectra at all potentials studied were typical of low-spin $c$-type hemes and the maximum $\alpha$-peak absorbance wavelength and shape did not change during the titration (Fig. 2b, inset). The MtrC hemes are reduced over a potential 

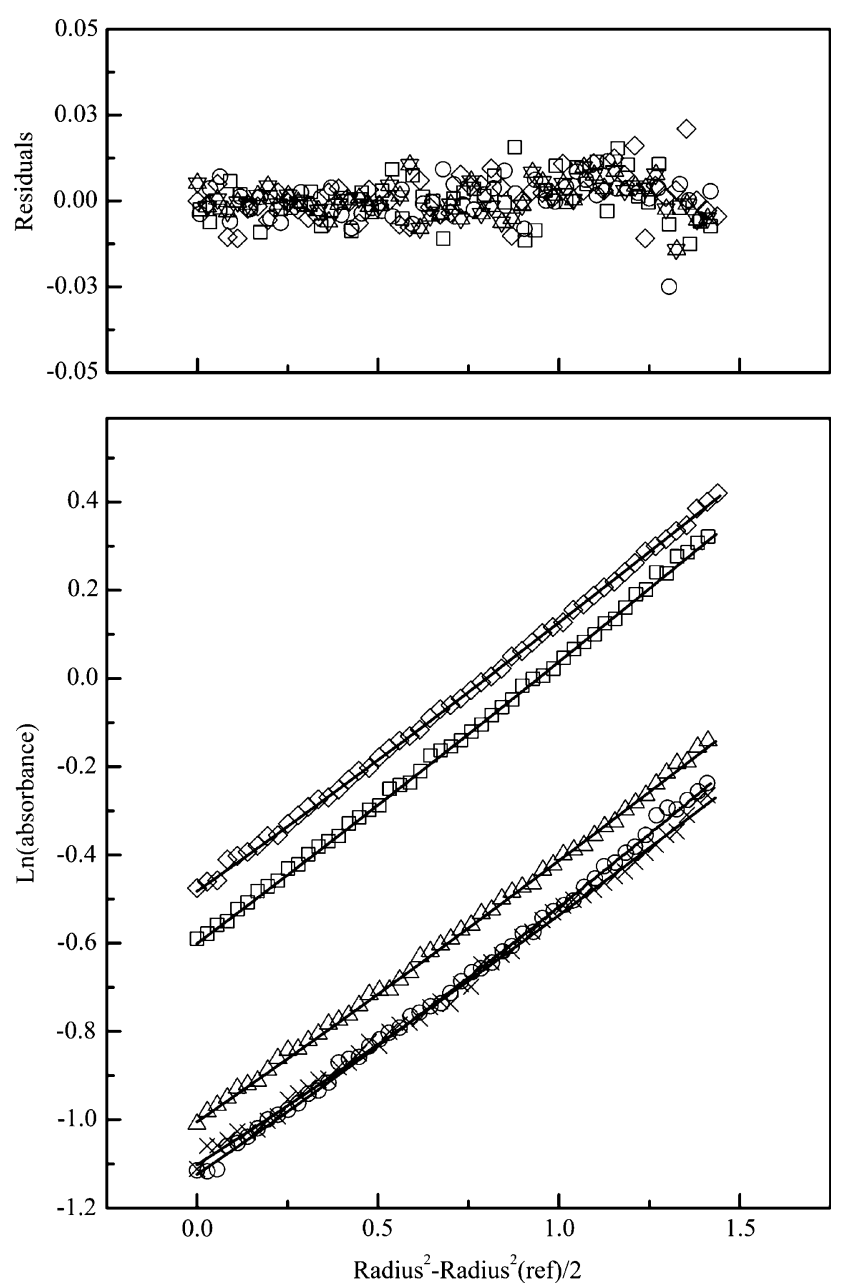

Fig. 4 Analytical ultracentrifugation (sedimentation equilibrium) analysis of MtrC. Lower panel: Absorbance profiles of MtrC at concentrations of $3 \mu \mathrm{M}$ (circles), $10 \mu \mathrm{M}$ (squares), $20 \mu \mathrm{M}$ (diamonds), $40 \mu \mathrm{M}$ (triangles) and $60 \mu \mathrm{M}$ (crosses) measured at 440 , $530,495,600$ and $620 \mathrm{~nm}$, respectively. For each concentration the data were globally fitted from centrifugation runs at 6,000, 8,000 and $10,000 \mathrm{rpm}(16 \mathrm{~h}$ at $293 \mathrm{~K})$ to the equation for a single-species, noninteracting model (solid lines). Conditions of measurement as follows: MtrC samples in $50 \mathrm{mM}$ HEPES, $\mathrm{pH} 7.5,150 \mathrm{mM} \mathrm{NaCl}$, $0.5 \%$ (wt/vol) CHAPS. Upper panel: Residuals between the experimental data and the fitted lines

window spanning approximately $500 \mathrm{mV}$, from fully oxidized $(+100 \mathrm{mV})$ to fully reduced $(-400 \mathrm{mV})$ (Fig. 2b). A simple monoheme protein $(n=1)$ titrates over approximately $200 \mathrm{mV}$ [27]. The broad potential range covered by MtrC redox chemistry reflects the presence of multiple heme centers with overlapping redox potentials, such that the contribution of individual hemes cannot be resolved. Multiple sequence alignments of MtrC homologues reveal the presence of 20 conserved histidines, ten in the $\mathrm{CXXCH}$ motifs and ten elsewhere in the primary structure. This would satisfy the required ligand sets for ten bishistidineligated low-spin $c$-type hemes. The electron-donating properties of histidine imidazole-ring nitrogen ligands to the heme iron stabilizes the oxidized Fe(III) state over the reduced $\mathrm{Fe}(\mathrm{II})$ state, thus resulting in more negative heme redox potentials compared with those of histidinemethionine-coordinated hemes [27]. Bishistidine heme coordination is thus consistent with the observed MtrC heme redox potentials.

Protein film voltammetry was also used to probe the redox chemistry of MtrC. Cyclic voltammograms of MtrC adsorbed onto a basal-plane graphite electrode and following subtraction of capacitive current revealed clear peaks corresponding to reduction (cathodic current) and oxidation (anodic current) of adsorbed MtrC molecules (Fig. 5, panel A). Signals were unchanged by electrode rotation or transfer of the MtrC-coated electrode to fresh buffer-electrolyte solution and were not observed in the absence of MtrC, which allows the signals to be attributed to direct redox transformation of MtrC. Exploration of more positive and negative potentials failed to identify additional redox activity from MtrC. The peak areas are almost identical for oxidative and reductive sweeps and hence the Faradaic current results from the stoichiometric reduction and oxidation of the $\mathrm{MtrC}$ hemes. Irrespective of $\mathrm{pH}$, a typical reduction or oxidation wave integrates to approximately $2 \mu \mathrm{C} \mathrm{cm}^{-2}$, from which MtrC coverage of the electrode is calculated as approximately $2 \mathrm{pmol} \mathrm{cm}^{-2}$. This is consistent with the formation of an electroactive monolayer of a protein the size of MtrC (approximately $85 \mathrm{kDa})$.

At $\mathrm{pH}$ 7.0, PFV shows that the complete reduction and subsequent reoxidation of MtrC hemes occurs between approximately +200 and $-400 \mathrm{mV}$ (vs. SHE). Again this is a much broader potential window (approximately $600 \mathrm{mV}$ ) than that anticipated for an independently titrating singleelectron center (approximately $200 \mathrm{mV}$ ) [35, 36]. As in the UV-vis absorption monitored potentiometric titration (Fig. 2b), this is consistent with the hemes within MtrC displaying a range of overlapping reduction potentials that contribute to the signal in an unresolved manner. Transfer of MtrC-coated electrodes into buffer-electrolyte of increasingly alkaline $\mathrm{pH}$ resulted in a negative shift of the noncatalytic signals, while the overall peak areas are retained (Fig. 5, panel B). The peaks display defined shoulders at $\mathrm{pH} 10$ and 11, illustrating that the heme redox potentials span a wider range here than at $\mathrm{pH} 7$. Coupling the transfer of one electron to one proton results in a uniform shift in peak potential of approximately $-48 \mathrm{mV}$ per $\mathrm{pH}$ unit $[35,36]$. The observation that the heme reduction potentials are more disparate at alkaline $\mathrm{pH}$ suggests the reduction of certain hemes within MtrC is coupled to protein protonation.

UV-vis monitored spectropotentiometry and noncatalytic PFV analyses provide information on the potential window over which MtrC is redox-active under conditions 


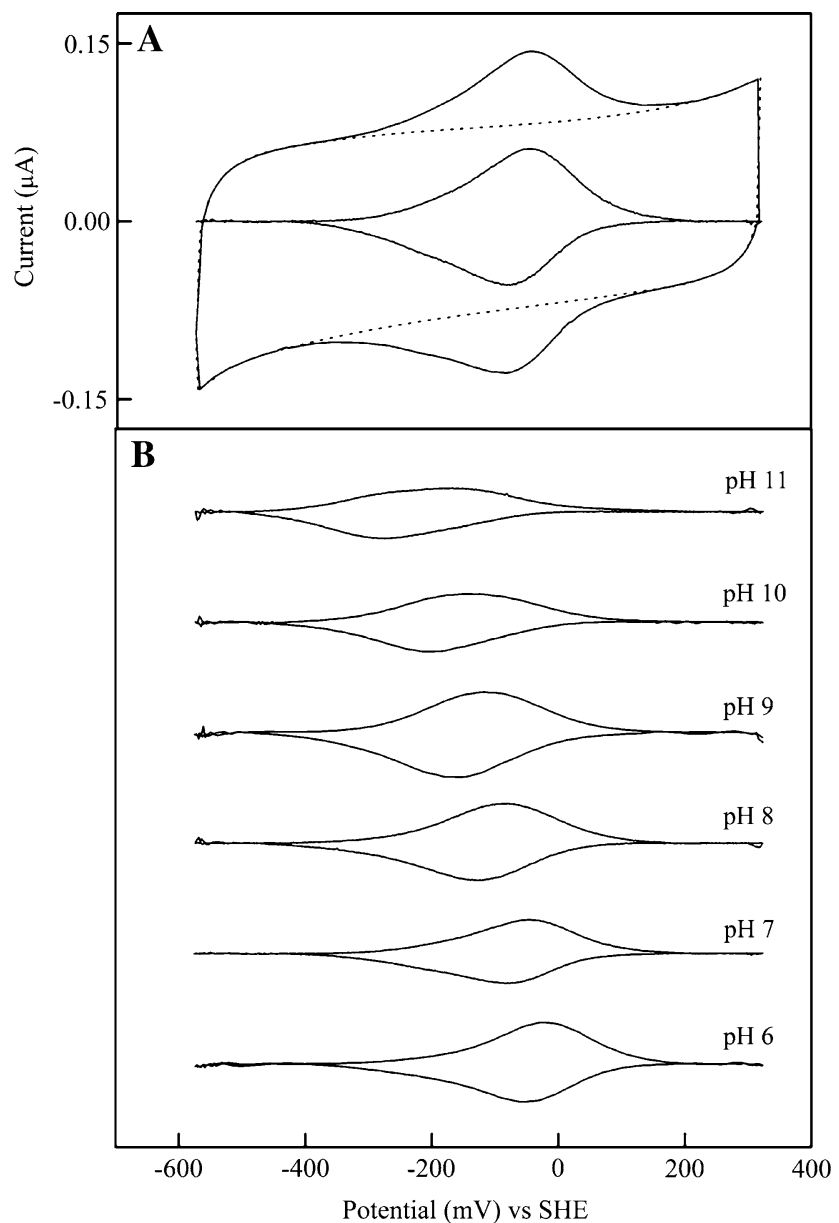

Fig. 5 Noncatalytic protein film voltammetry of MtrC. A Cyclic voltammogram of adsorbed MtrC. The dotted line is the electrode response in the absence of an $\mathrm{MtrC}$ protein film. The bufferelectrolyte is $50 \mathrm{mM}$ HEPES, $100 \mathrm{mM} \mathrm{NaCl}, \mathrm{pH} 7.0$; scan rate $30 \mathrm{mV} \mathrm{s}^{-1}$, temperature $273 \mathrm{~K}$. In the middle is the bare electrode "baseline" response subtracted from the MtrC coated electrode response. $B$ The effect of $\mathrm{pH}$ on $\mathrm{MtrC}$ cyclic voltammetry. Representative baseline-subtracted, normalized responses of $\mathrm{MtrC}$ in $100 \mathrm{mM} \mathrm{NaCl}, 50 \mathrm{mM}$ MES, HEPES, CHES or CAPS at $\mathrm{pH} 6.0$, 7.0, 8.0, 9.0, 10.0 and 11.0 as indicated; scan rate $30 \mathrm{mV} \mathrm{s}^{-1}$, temperature $273 \mathrm{~K}$

in which potential control over the sample is imposed while the analysis is performed. However, neither technique resolves the behavior of individual (sets of) hemes. For this reason samples of MtrC were poised electrodically at defined potentials in a carbon pot and transferred to EPR tubes for spectroscopic analyses (Fig. 3b). As the potential of the poised sample was lowered from +100 to $-150 \mathrm{mV}$, the broad $g_{\max } \sim 3.7-2.7$ region changed shape, most notably decreasing in breadth. For samples poised at potentials of -150 and $-175 \mathrm{mV}$ the shape change becomes more dramatic, with a sharp, intense resonance appearing at $g=2.9$ and an associated derivative signal appearing at $g=2.2$ (Fig. 3b, spectra d, e). These EPR signals are characteristic of the $g_{1}$ and $g_{2}$ components of rhombic signals arising from low-spin bishistidine-ligated $\mathrm{Fe}$ (III) hemes with near-parallel imidazole planes [27, 33]. The appearance of these features during the reductive titration is suggestive of magnetic coupling between two, or more, low-spin heme centers in the fully oxidized protein [37]. For example, if two magnetically spin-coupled low-spin $\mathrm{Fe}$ (III) hemes have sufficiently distinct reduction potentials, reduction of one of these hemes to the $S=0$ low-spin $\mathrm{Fe}(\mathrm{II})$ state "uncouples" the previously EPRsilent spin-coupled $S=1 / 2 \mathrm{Fe}$ (III) heme.

In MtrC samples poised below $-175 \mathrm{mV}$ the intensity of the $g=2.9$ and 2.2 resonances decreased progressively (Fig. 3b, spectra e-j). Owing to the overlap with other signals, accurate integration of the rhombic trio at $g=2.9$, 2.2 and 1.5 was prevented for samples poised above $-400 \mathrm{mV}$. However, the signal was sufficiently resolved in the sample poised at $-450 \mathrm{mV}$ to allow informative integration and this yielded a value of 1.3 hemes per $\mathrm{MtrC}$ molecule. Given that the signal intensity of the sample poised at $-450 \mathrm{mV}$ accounts for approximately $40 \%$ of the signal intensity from the sample poised at $-175 \mathrm{mV}$ (Fig. 3b, spectrum e), we tentatively attribute contributions from up to three magnetically isolated $S=1 / 2 \mathrm{Fe}$ (III) hemes to the signal seen at the higher potential. While the EPR spectra from MtrC are clearly complex, with more features than we have discussed explicitly here, we have succeeded in resolving contributions from spin-coupled and magnetically isolated hemes over distinct potential ranges. Many of the EPR-detectable hemes titrate over a similar potential range to that evident from the UV-vis/PFV analyses. Exceptions are those hemes that are still EPR-detectable, i.e., oxidized, in samples poised below $-400 \mathrm{mV}$. However, in these experiments potential control is lost as soon as the sample is removed from the carbon pot for transfer to the EPR tube. Thus, it is quite possible that some positive drift of the sample potential occurs prior to EPR analysis and that this is likely to be more pronounced in samples poised at the lower, as opposed to higher, potentials. With this in mind, the results of both spectropotentiometric analyses and PFV appear to be in good agreement.

\section{Electron transfer kinetics of MtrC}

To examine the ability of MtrC to transfer electrons to a solid electrode surface, interfacial electron transfer kinetics were probed using PFV. By monitoring the position of the reductive $\left(E_{\mathrm{p}}^{\mathrm{c}}\right)$ and oxidative $\left(E_{\mathrm{p}}^{\mathrm{a}}\right)$ peaks as a function of scan rate (Fig. 6) and using Trumpet plot analysis [38], we estimate a standard heterogeneous rate constant of approximately $100 \mathrm{~s}^{-1}$. The overlapping contribution from ten heme centers under each peak prevents rigorous kinetic quantitation; however, the value is within the range 


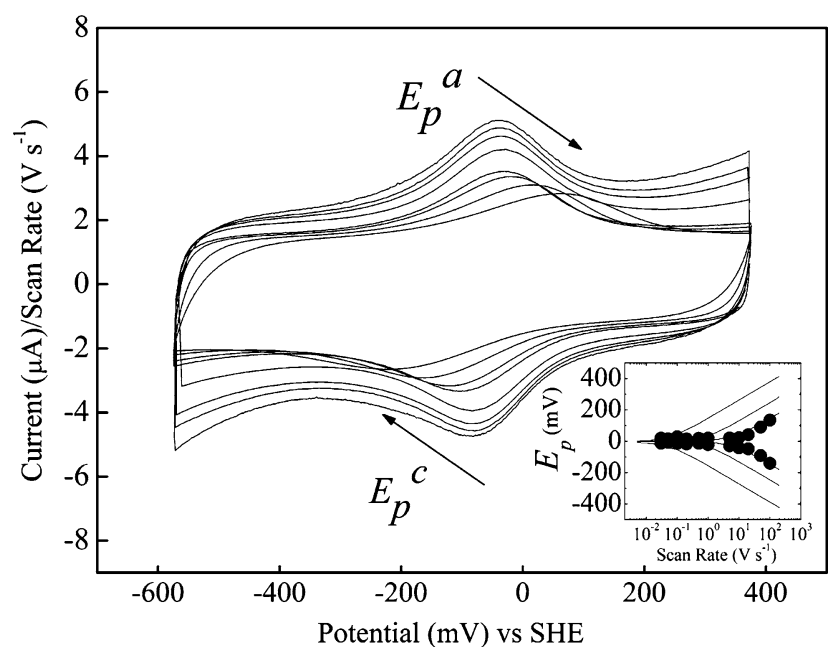

Fig. 6 The scan-rate dependence of MtrC noncatalytic protein film voltammetry. Cyclic voltammograms of MtrC at scan rates of 0.03 , $0.05,0.1,0.5,10,20,50$ and $100 \mathrm{~V} \mathrm{~s}^{-1}$. The arrows indicate increasing scan rate. Inset: Variation of the oxidative $\left(E_{p}^{a}\right)$ and reductive $\left(E_{p}^{c}\right)$ peak potentials (circles) with scan rate. Trumpet plots were generated with heterogeneous rate constants of $1 \mathrm{~s}^{-1}, 10 \mathrm{~s}^{-1}$ and $100 \mathrm{~s}^{-1}$. Buffer-electrolyte $50 \mathrm{mM}$ HEPES, $100 \mathrm{mM} \mathrm{NaCl}, \mathrm{pH}$ $7.0,273 \mathrm{~K}$

displayed by intracellular redox proteins considered to undergo facile interfacial electron exchange in similar experiments [36] and indicates that MtrC contains a heme arrangement compatible with facile electron exchange with solid surfaces.

Electron transfer kinetics were probed further in voltammetric experiments in which the electrode substituted the role of intracellular electron transfer proteins in delivering electrons to MtrC. The subsequent rate at which MtrC could mediate electron transfer to iron(III) citrate, a model respiratory Fe(III) substrate of S. oneidensis MR-1 [11, 17], was then quantitated. Iron(III) citrate speciation is complex, with a number of different mononuclear and polynuclear species able to form in aqueous solution in a concentration-dependent manner [39]. Nevertheless, welldefined "sigmoidal" reduction waves were observed when $\mathrm{MtrC}$-coated electrodes were placed in solutions of iro$\mathrm{n}$ (III) citrate and rotated at 3,000 rpm (to negate substrate mass-transport effects) (Fig. 7). Significantly, the steepest region of the catalytic wave corresponds to the potential window where the nonturnover peaks from MtrC are observed, indicating that in the presence of substrate, as hemes are reduced, the enzyme is "switched on" (Fig. 7a). Voltammetry of iron(III) citrate solutions with rotated "bare" graphite electrodes in the absence of MtrC films displayed iron(III) citrate reduction, but this nonspecific response was always clearly distinguishable in shape from that of the MtrC-mediated catalytic response (Fig. 7a). Analysis of the magnitude of the catalytic current was
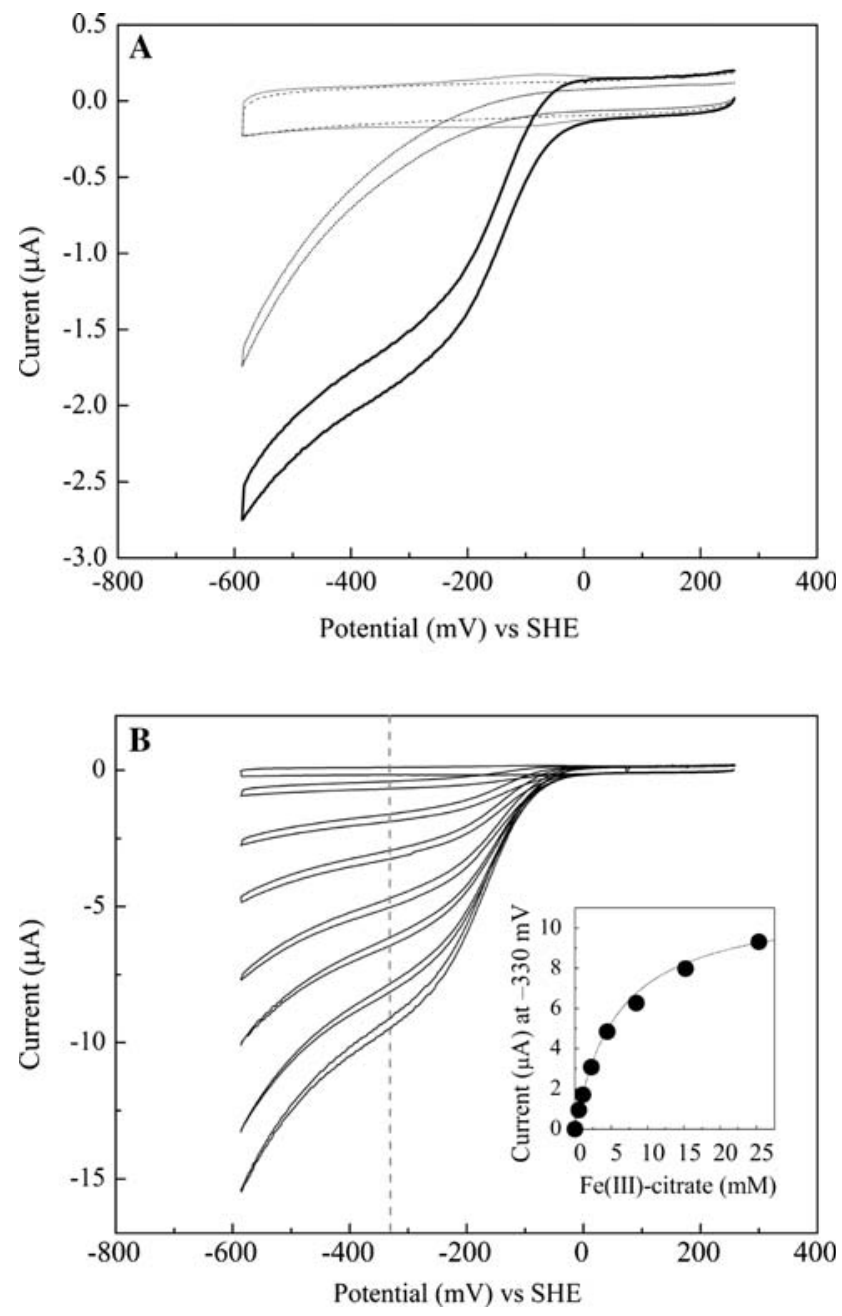

Fig. 7 Catalytic protein film voltammetry of MtrC. a Typical cyclic voltammograms illustrating the reduction of $1 \mathrm{mM}$ iron(III) citrate by MtrC adsorbed on a basal-plane graphite electrode (heavy solid line) and by the basal-plane graphite electrode in the absence of adsorbed $\mathrm{MtrC}$ (dotted line). Also displayed are the voltammetric responses of $\mathrm{MtrC}$ in the absence of iron(III) citrate (light solid line) and the bare electrode in the absence of MtrC and iron(III) citrate (dashed line). $\mathbf{b}$ Typical cyclic voltammograms from an MtrC film in $0,0.5,1,2,4.5$, 9, 16 and $25 \mathrm{mM}$ iron(III) citrate. The electrochemical potential $(-330 \mathrm{mV})$ where the catalytic current was analyzed is illustrated by a broken gray line. Buffer-electrolyte $50 \mathrm{mM}$ HEPES, $100 \mathrm{mM}$ $\mathrm{NaCl}, \mathrm{pH} 7.0$, scan rate $30 \mathrm{mV} \mathrm{s}^{-1}$, electrode rotation $3,000 \mathrm{rpm}$, temperature 293 K. Inset: Variation of the magnitude of the catalytic current, measured at $-330 \mathrm{mV}$, with iron(III) citrate concentration. The line describes the catalytic current arising from a MichaelisMenten description of enzyme kinetics with a Michaelis constant of $6 \mathrm{mM}$ and a turnover number of $430 \mathrm{~s}^{-1}$

performed at $-330 \mathrm{mV}$ to minimize reductive contributions to the current from the bare electrode while maximizing the contribution from $\mathrm{MtrC}$. The current at $-330 \mathrm{mV}$ in the presence of $\mathrm{MtrC}$, but prior to iron(III) citrate addition, was taken as the zero-substrate response. The catalytic current (rate) displayed saturating behavior on increasing the iron(III) citrate concentration (Fig. 7b). 
Fitting to the Michaelis-Menten equation yielded a Michaelis constant of $6 \pm 2 \mathrm{mM}$ and a turnover number of $430 \mathrm{~s}^{-1}$. These numbers should be considered as upper limits for these kinetic parameters since we cannot exclude some contribution to catalytic currents from electrodic reduction of iron(III) citrate at the higher concentrations used.

It is clear that MtrC can achieve a rate of iron(III) citrate reduction comparable to that achieved by intracellular respiratory reductases with their substrates. No MtrCdependent catalytic currents could be observed with nitrate or nitrite, alternative respiratory substrates of $S$. oneidensis. Efforts to explore "solid" Fe(III) substrates, such as amorphous iron(III) oxide, were hindered by interference from electrodic reduction. Nevertheless, the results demonstrate that MtrC can mediate electron transfer to an $\mathrm{Fe}$ (III) substrate in a potential window that corresponds with the redox properties of the enzyme determined from equilibrium potentiometric titrations. The results are consistent with the reduced capacity of $S$. oneidensis to grow on iron(III) citrate in $\Delta m t r C$ mutants $[11,17]$.

\section{Discussion}

The spectropotentiometric and voltammetric analysis of MtrC provides the first insights into the thermodynamic and kinetic properties of the multiheme cytochrome proposed to mediate electron transfer to extracellular electron acceptors. Solution-state potentiometry and PFV revealed that the hemes within MtrC reversibly titrate between fully oxidized and fully reduced states over a redox potential range of approximately +100 and $-400 \mathrm{mV}$ (vs. SHE). This broad potential range reflects the composite titrations of ten hemes that precludes resolution of individual heme redox potentials. It could be argued that the operating potentials of the MtrC hemes would be significantly modified on engagement with a solid mineral surface. Our view is that any change will be negligible since we find $\mathrm{MtrC}$ redox activity occurs over a similar potential range when MtrC is in solution, monitored using UV-vis spectropotentiometry, and when it is adsorbed on a solid surface, probed using PFV. It is interesting to note that whole-cell voltammetry of Shewanella species anaerobically grown (conditions where we would expect MtrC to be synthesized) and adsorbed on glassy carbon electrodes revealed reversible reduction and oxidation peaks centered at approximately $-100 \mathrm{mV}$ (vs. SHE) [24, 25], a similar behavior to that presented here for MtrC. This suggests that intact cells with MtrC exposed on the outer-cell surface exchange electrons with solid substrates over a similar potential window as the redox chemistry determined here for the purified protein.
EPR spectropotentiometry of MtrC gave complex spectra that included signals likely to arise from magnetically isolated and magnetically interacting hemes. Complex heme-heme interactions have been reported in other multiheme cytochromes such as the decaheme NrfA homodimer [40] and the 24-heme hydroxylamine oxidoreductase homotrimer [37, 41] and it is only through structure-based spectral deconvolutions that spectral features have be assigned to individual heme pairs or triads [40, 41]. At present, despite extensive efforts, the structure of MtrC is not known; however, primary structure analysis suggests that it, and also periplasmic decaheme MtrA [10], encodes two approximately 150 amino acid pentaheme modules with similarity to the pentaheme NrfB, an approximately 150 amino acid pentaheme periplasmic electron transport cytochrome widely involved in nitrite respiratory systems. All five hemes within NrfB are bishistidine-coordinated and it exhibits thermodynamic activity over a similar potential domain to MtrC [42].

Like MtrC, the other multiheme cytochromes suggested to be involved in transferring electrons to the outer membrane from $\mathrm{MQH}_{2}$ in the inner membrane also bind bishistidine-coordinated low-potential hemes. These proteins include CymA, a tetraheme $c$-type cytochrome anchored to the inner membrane that serves as a $\mathrm{MQH}_{2}$ dehydrogenase [8, 12, 20, 43, 44]; Stc, a 12-kDa tetraheme periplasmic $c$-type cytochrome $[15,45]$ and the periplasmic decaheme cytochrome MtrA [10] (Fig. 1). CymA is not thought to be a proton-motive quinol dehydrogenase and thus the electron transfer from quinol to MtrC is not energy conserving. Depending on growth conditions, electrons could enter the $\mathrm{MQH}_{2}$ pool via the activity of primary dehydrogenases, such as NADH dehydrogenase, formate dehydrogenase or hydrogenase. The redox potential of the $\mathrm{NAD} / \mathrm{NADH}, \mathrm{CO}_{2} / \mathrm{HCOO}^{-}$or $2 \mathrm{H}^{+} / \mathrm{H}_{2}$ couples in the cell will be approximately -300 to $-400 \mathrm{mV}$ and that of $\mathrm{MQ} /$ $\mathrm{MQH}_{2}$ approximately -50 to $-100 \mathrm{mV}$. This thermodynamic free energy gap $(\Delta E \sim 300-400 \mathrm{mV})$ is sufficient to allow for generation of a proton-motive force (approximately $200 \mathrm{mV}$ ) through coupling electron transport to either proton translocation (NADH dehydrogenase) or an electrogenic redox loop (formate dehydrogenase or hydrogenase) (Fig. 1). Thus, in terms of bioenergetics, the energy-conservation associated with respiration of extracellular $\mathrm{Fe}(\mathrm{III})$ is most likely to be associated with electron input into the MQ pool (reduction of MQ to $\mathrm{MQH}_{2}$ ), with the multiheme conduit linking $\mathrm{MQH}_{2}$ to $\mathrm{Fe}$ (III) minerals simply serving to harness $\mathrm{Fe}(\mathrm{III})$ reduction as a means to recycle MQ (Fig. 1). This makes it bioenergetically equivalent to the well-characterized bacterial periplasmic nitrate reductase system [5] that is also present in $S$. oneidensis MR-1 (Fig. 1). At this stage the actual operating potentials of individual hemes in the conduit is unknown, 
since injection of one electron into a multiheme cytochrome can change the potential of a neighboring heme. This has been studied in some detail for hydroxylamine oxidoreductase and the tetraheme cytochrome $c$-554 [46] and could be yet more complex for a decaheme cytochrome. Furthermore, it is not clear if all the hemes in the system need be involved. Nevertheless the role for Fe(III) reduction in recycling the MQ pool negates the need for a large $\Delta E$ between the $\mathrm{MQH}_{2}$ and the multiheme cytochrome chain to drive a proton-motive step. There simply needs to be sufficient driving force to allow electron transfer to proceed through the low-potential heme conduit and this can be envisaged when the $\mathrm{MQ} / \mathrm{MQH}_{2}$ is predominantly reduced and there is strong oxidant such as an $\mathrm{Fe}(\mathrm{III})$ mineral oxide to draw electrons through the system.

In closing, it is not immediately clear why $\mathrm{MtrC}$ need be a decaheme cytochrome to achieve the one-electron reduction of $\mathrm{Fe}(\mathrm{III})$. In the intact cell, MtrC will receive electrons from the CymA-Stc-MtrA conduit that mediates electron transfer between the inner and the outer membrane and the multiheme nature of this conduit may represent an efficient means to achieve electron transfer across the approximately $150 \AA$ that separates these two membranes (Fig. 1). It may be that the multiheme nature of the outermembrane MtrC is also important for moving electrons long distances, but in this case this might be away from the outer membrane through extracellular lipopolysaccharide to the extracellular substrate. Having an extracellular enzyme with many hemes available as potential one-electron output sites may also serve to facilitate productive interaction with minerals in the environment that are likely to present chemically and topographically diverse substrates. Further insights into the role of the ten hemes will require the resolution of the tertiary structure to MtrC to resolve the molecular organization of these cofactors.

Acknowledgements This work was supported by Schlumberger, the US Department of Energy Biogeochemistry Grand Challenge, the UK Biotechnology and Biological Sciences Research Council grants B18695 and BBSSA200410938 and a JIF award (062178). The Pacific Northwest National Laboratory is operated for the Department of Energy by the Battelle Memorial Institute, contract DE-AC0576RLO1830. We thank Ann Reilly for invaluable technical support and Andy Gates and Clive Butler for valuable help and discussion.

\section{References}

1. Venkateswaren K, Moser DP, Dollhopf ME, Lies DP, Saffarini DA, Macgregor BJ, Ringelberg DB, White DC, Nishijima M, Sano H et al (1999) Int J Syst Bacteriol 49:705-724

2. Nealson KH, Scott J (2003) In: Dworkin M (ed) The prokaryotes, vol 2004. Springer, New York

3. Heidelberg JF, Paulsen IT, Nelson KE, Gaidos EJ, Nelson WC, Read TD, Eisen JA, Seshadri R, Ward N, Methe B, Clayton RA et al (2002) Nat Biotechnol 20:1118-11123
4. Nealson KH, Belz A, McKee B (2002) Antonie Van Leeuwenhoek Int J Gem M 81:215-222

5. Richardson DJ (2000) Microbiol 146:551-571

6. Nealson KH, Saffarini D (1994) Annu Rev Microbiol 48:311-343

7. Fredrickson JK, Zachara JM, Kennedy DW, Dong HL, Onstott TC, Hinman NW, Li SM (1998) Geochim Cosmochim Acta 62:3239-3257

8. Myers C, Myers J (1992) J Bacteriol 174:3429-3438

9. Myers C, Myers J (1993) FEMS Microbiol Lett 108:15-22

10. Pitts KE, Dobbin PS, Reyes-Ramirez F, Thomson AJ, Richardson DJ, Seward HE (2003) J Biol Chem 278:27758-27765

11. Beliaev AS, Saffarini DA, McLaughlin JL, Hunnicutt D (2001) Mol Microbiol 39:722-730

12. Myers CR, Myers JM, (1997) J Bacteriol 179:1143-1152

13. Myers CR, Myers JM (2003) Lett Appl Microbiol 37:254-258

14. Gordon EHJ, Pike AD, Hill AE, Cuthbertson PM, Chapman SK, Reid GA (2000) Biochem J 349:153-158

15. Tsapin AI, Vandenberghe I, Nealson KH, Scott JH, Meyer TE, Cusanovich MA, Harada E, Kaizu T, Akutsu H, Leys D, Van Beeumen JJ (2001) Appl Environ Microbiol 67:3236-3244

16. Dobbin PS, Butt JN, Powell A, Reid GA, Richardson DJ (1999) Biochem J 342:439-448

17. Myers JM, Myers CR (2002) Appl Environ Microbiol 68:27812793

18. Myers JM, Myers CR (2001) Appl Environ Microbiol 67:260269

19. Beliaev AS, Saffarini DA (1998) J Bacteriol 180:6292-6297

20. Field SJ, Dobbin PS, Cheesman MR, Watmough NJ, Thomson AJ, Richardson DJ (2000) J Biol Chem 275:8515-22

21. Shi L, Chen B, Wang Z, Elias DA, Mayer MU, Gorby YA, Ni S, Lower BH, Kennedy DW, Wunschel DS, Mottaz HM, Marshall MJ, Hill EA, Beliaev AS, Zachara JM, Fredrickson JK, Squier TC (2006) J Bacteriol 188:4705-4714

22. Myers CR, Myers JM (2004) Lett Appl Microbiol 39:466-70

23. Kim HJ, Park HS, Hyun MS, Chang IS (2002) Enzyme Microb Technol 30:145-152

24. Kim BH, Kim HJ, Hyun MS, Park DH (1999) Microbiol Biotechnol 9:127-131

25. Shi L, Lin JT, Markillie LM, Squier TC, Hooker BS (2005) Biotechniques 38:297

26. Berry E, Trumpower B (1987) Anal Biochem 161:1-15

27. Moore GR, Pettigrew GW (1990) Cytochromes $c$ : evolutionary, structural and physicochemical aspects. Springer, New York

28. Dutton PL (1978) Methods Enzymol 54:411-435

29. Aasa R, Vanguard T (1975) J Magn Reson 19:308-315

30. Philo JM (1997) Biophys J 72:435-444

31. Demeller B (2005) http://www.ultrascan.uthscsa.edu/

32. Anderson LJ, Richardson DJ, Butt JN (2001) Biochemistry 40:11294-11307

33. Walker FA (1999) Coord Chem Rev 186:471-534

34. Horan T, Wen J, Arakawa T, Liui N, Brankow D, Hu S, Ratzkin B, Philo JS (1995) J Biol Chem 270:24604-24608

35. Almeida MG, Silveira CM, Guigliarelli B, Bertrand P, Moura JJG, Moura I, Leger C (2007) FEBS Lett 581:284-288

36. Bard AJ, Faulkner LR (2001) Electrochemical methods: fundamentals and applications, 2nd edn. Wiley, New York

37. Hendrich MP, Petasis D, Arciero DM, Hooper AB (2001) J Am Chem Soc 123:2997-3005

38. Hirst J, Armstrong FA (1998) Anal Chem 70:5062-5071

39. Gautier-Luneau I, Merle C, Phanon D, Lebrun C, Biaso F, Serratrice G, Pierre JL (2005) Chemistry 11:2207-2219

40. Bamford VA, Angrove HC, Seward HE, Thomson AJ, Cole JA, Butt JN, Hemmings AM, Richardson DJ (2002) Biochemistry 41:2921-2931

41. Hendrich MP, Logan M, Andersson KK, Arciero DM, Lipscomb JD, Hooper AB (1994) J Am Chem Soc 116:11961-11968 
42. Clarke TA, Dennison V, Seward HE, Burlat B, Cole JA, Hemmings AM, Richardson DJ (2004) J Biol Chem 279:41333-41339

43. Myers CR, Myers JM (1994) J Appl Bacteriol 76:253-258

44. Schwalb C, Chapman SK, Reid GA (2003) Biochemistry 42:9491-9497
45. Leys D, Meyer TE, Tsapin AS, Nealson KH, Cusanovich MA, Van Beeumen JJ (2002) J Biol Chem 277:35703-25711

46. Kurnikov IV, Ratner MA, Pacheco A (2005) Biochemistry 44:1856-1863 